AIAA-2002-1447

\title{
Helicopter Vibration Reduction in Forward Flight using Blade Integral Twist Control
}

\author{
SangJoon Shin* and Carlos E. S. Cesnik ${ }^{\dagger}$ \\ Department of Aerospace Engineering \\ The University of Michigan, Ann Arbor, Michigan
}

\begin{abstract}
Active integral twist control for vibration reduction of helicopter rotors during forward flight is investigated in this paper. The twist deformation is obtained using anisotropic piezocomposite actuators embedded in the composite blade construction. An analytical framework has been developed to examine integrally-twisted helicopter blades and their aeroelastic behavior during forward flight condition. This is accomplished by modifying an existing multi-body dynamics code, DYMORE, with active material constitutive relations. An Active Twist Rotor (ATR) blade was designed in accordance with this framework. A four-bladed fully-articulated ATR system was built and tested to demonstrate the present concept in forward flight. In parallel, the impact of the integral twist actuation upon the fixed- and rotating-system loads during forward flight is estimated by the proposed analysis. While discrepancies are found in the amplitude of the loads under actuation, the predicted trend of load variation with respect to its control phase correlates well with the experiments. Using the analysis, system identification is performed to estimate the harmonic transfer functions of the ATR system based on linear time-periodic (LTP) approach. A vibration minimizing closed-loop controller can then be designed based on this system identification results.
\end{abstract}

\section{INTRODUCTION}

Rotorcraft has been a very important means of aerial transportation due to its capability of vertical take-off and landing. However, it has also been under some serious constraints such as relatively poor ride quality associated with high levels of vibration and noise, restricted flight envelope, low fatigue life of the structural components, and consequently high operating cost. The primary source of these high levels of vibration is the complex unsteady aerodynamic environment which is generated near the rotor blades mainly

\footnotetext{
* Post doctoral fellow. Member, AIAA. Member, AHS.

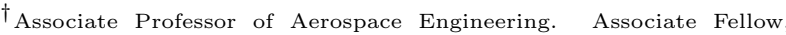
AIAA. Member, AHS

Copyright(C) 2002 by SangJoon Shin and Carlos E. S. Cesnik. Published by the American Institute of Aeronautics and Astronautics, Inc. with permission.
}

during forward flight. An instantaneous asymmetry of the aerodynamic loads acting on the blade at different azimuth location is developed, and such asymmetry becomes more and more adverse as the forward flight speed increases. The coupling between the structural and mechanical components such as rotor, fuselage, engine, and transmission adds another degree of complexity to this problem. There have been considerable efforts in the helicopter community to reduce such vibration, and most of them were based on passive methodologies [1]. However, during the last two decades, active methods to alleviate helicopter vibration based on the idea of directly modifying unsteady aerodynamic loads acting upon the rotor blades have been studied. These may be broadly classified as higher harmonic control (HHC) and individual blade control (IBC) $[2,3]$. Several outstanding results were obtained in terms of vibration reduction capability. Examples include analytical studies searching for an optimal control scheme [4], wind tunnel tests with either small or full-scaled model $[2,5]$, and flight tests [6]. However, these realizations are associated with employing additional hydraulic actuators installed on either non-rotating (beneath swashplate) or rotating frames (between pitch links) have not successfully entered into full-scale application. Typical disadvantages were identified, such as adverse power requirement and limitation on excitation frequency in $\mathrm{HHC}$, and extreme mechanical complexity of hydraulic sliprings in IBC.

Recently, advances in active materials have enabled multiple lightweight sensors/actuators embedded or surface-mounted at several locations in rotor blades $[7,8,9]$. By employing active materials for such actuators, one can potentially obtain advantages in terms of weight and power consumption when compared with traditional hydraulic systems. Various implementations have been suggested for active materials application to the rotorcraft vibration reduction [10]. Among those implementations, an integral twist actuation concept $[11,12,13,14]$ is selected as a major mechanism for blade control in this present study. This actuation concept presents itself as an aggressive alternative with several potential benefits. Besides providing redundancy in operation, the integral concept does not increase the profile drag of the blade unlike discrete flap concepts. 
Moreover, the actuators once embedded in the composite construction become part of the load bearing structure, making the active blade a truly integrated multifunctional structure that allows for effective construction and assembly of future low vibration and low noise rotor blades.

The integral twist actuation concept using active materials technology has showed promising benefits from a conceptual standpoint [15], as well as preliminary hover testing with small-scaled models $[13,16]$. In the Boeing/MIT integral blade program [13] sponsored by DARPA, a 1/6th Mach-scaled $\mathrm{CH}-47 \mathrm{D}$ blade was manufactured and hover tested in a two-bladed rotor configuration, where the integral twist actuation was obtained through the use of Active Fiber Composite (AFC). In order to design the blade structure and predict the actuation performance, a rudimentary singlecell active composite beam model [17] was used. Also, an intentional reduction by $50 \%$ on the baseline torsional stiffness was imposed and regarded to improve twist actuation. Hover testing on the MIT Hover Test Stand Facility demonstrated tip twist performance between $1^{\circ}$ and $1.5^{\circ}$ in the rotating environment. Boeing/MIT continues this work that should eventually lead to forward flight wind-tunnel test and full-scale blade section manufacturing [18].

However, a comprehensive investigation on the helicopter vibration reduction, which is obtained by the present integral actuation concept, has not been started until a recent open-loop wind-tunnel forward flight test [19]. This open-loop test was conducted under the Active Twist Rotor (ATR) program, a collaborative research between the U.S. Army Research Laboratory, at NASA Langley Research Center, and MIT. The research activities which have been conducted so far under this program are described in detail in the relevant references: structural modeling of the integral blades [20], blade design, prototyping, and its bench test [21], hover test and its correlation with analysis [16, 22], openloop forward flight test and its correlation with analysis $[19,23]$, and a preliminary numerical simulation of the closed-loop control [24].

This paper presents the latest results from the ATR research, especially regarding the open-loop forward flight analysis, its correlation with experiments, and system identification. It illustrates a framework which simulates a response of the helicopter rotor system employing active composite blade with distributed anisotropic piezoelectric strain actuators during forward flight. An active blade of such rotor system is analyzed in a two-step approach as follows. First, its cross section is modeled as a multi-cell composite beam with integral anisotropic actuators [20, 25]. Then, this crosssectional result is added to the existing multi-body dynamics model for passive helicopter blades [26], which already combines a geometrically-exact beam structural formulation and the finite-state dynamic inflow theory for aerodynamics [27]. Results from the open-loop forward flight experiment are correlated with the prediction from the simulation. Using the forward flight analysis proposed above, system identification is conducted to estimate the harmonic transfer functions of the ATR system [28, 29]. Within this effort, linear time-periodic (LTP) components of these transfer functions are extracted in addition to linear time-invariant (LTI) members. Since the helicopter rotor becomes a LTP system during forward flight due to a periodicity in aerodynamics, these LTP components potentially exist and may contribute to the identification results. The specific objectives of this paper are:

1. Build an aeroelastic framework to simulate helicopter forward flight with active twist rotor blades and evaluate its response due to actuation

2. Correlate the analytical prediction with experiment results for the open-loop control ATR test in forward flight

3. Identify the harmonic transfer functions of the ATR system during forward flight based on LTP system approach.

\section{FRAMEWORK}

For analyzing helicopter blades with embedded strain actuators, a framework is needed such that the effects of the active material embedded in the structure are carried out throughout all the steps of the analysis. Since there are few analysis formulations available which can properly handle all the peculiarities of an active helicopter blade cross section like the ATR, the authors have been working on creating a general framework for active rotor blade modeling. Here, an asymptotical analysis takes the electromechanical three-dimensional problem and reduces it into a set of two analyses: a linear analysis over the cross section and a nonlinear analysis of the resulting beam reference line. By coupling the active blade formulation with the appropriate unsteady aerodynamics, the aeroelastic problem can then be solved in time and simulations be conducted for control design. A schematic diagram of the established framework is shown in Fig. 1.

\section{Cross-Sectional Analysis}

Stiffness and actuation forcing constants for an active anisotropic thin-walled two-cell beam are obtained from a variational-asymptotical formulation [20]. While restricted to thin-walled beams, it yields closed form solutions of the displacement field (which is derived and not assumed), and stiffness and actuation constants. 


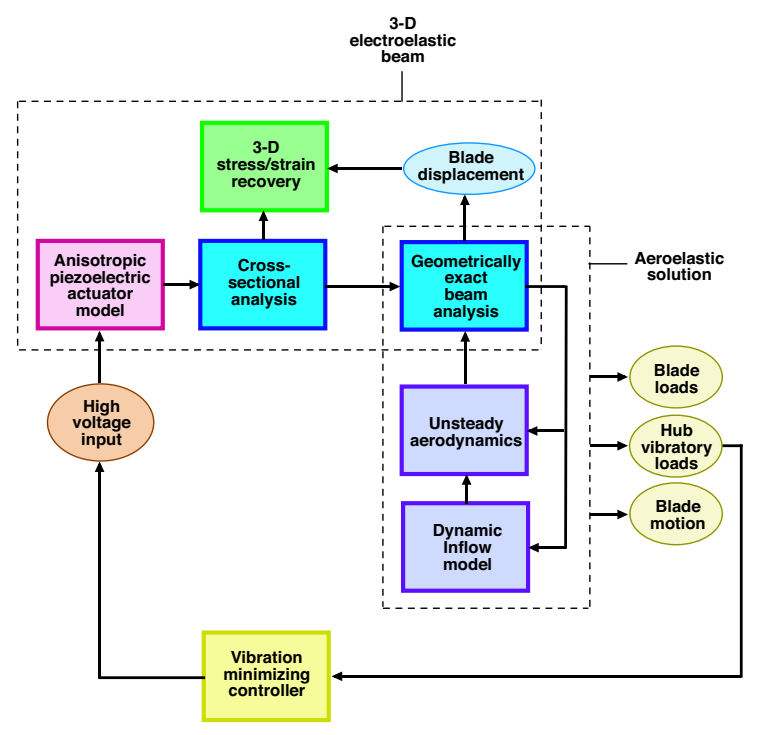

Figure 1: Schematic diagram of the analytical framework for an active helicopter blade and its aeroelastic behavior

The availability of correct closed form expressions is essential to determine design paradigms on this new type of blade, mainly concerning the tradeoffs between torsional stiffness and twist actuation. These stiffness and actuation constants are then used in the beam finite element discretization of the blade reference line.

\section{Blade Structure and Aerodynamic Analyses}

To simulate the active rotor system for open and closed-loop control, a time domain formulation is needed. The multi-body dynamics code DYMORE, developed by Bauchau and co-workers [26], is based on the geometrically-exact beam equations and it is coupled to the aerodynamics of Peters and He [27]. DYMORE's original beam formulation is consistent with the one used previously by the authors in studying hover response of the ATR system. The difference now is that the formulation is displacement-based instead of mixedform. Therefore, the same cross-sectional analysis for active beams can be used. The integral actuation forces and moments existing inside the blade structure are realized in the form of finite element loads to the passive beam in the modified time domain analysis. The solution of the 1-D beam analysis provides blade displacement and generalized stress fields due to external loading and piezoelectric actuation, which are of interest in the analysis of static and dynamic deformations and aeroelastic stability.

The forward flight part of the finite-state dynamic inflow aerodynamics model [27] was already implemented in DYMORE. This aerodynamic theory was originally developed for both hover and forward flight conditions. This model was constructed by applying
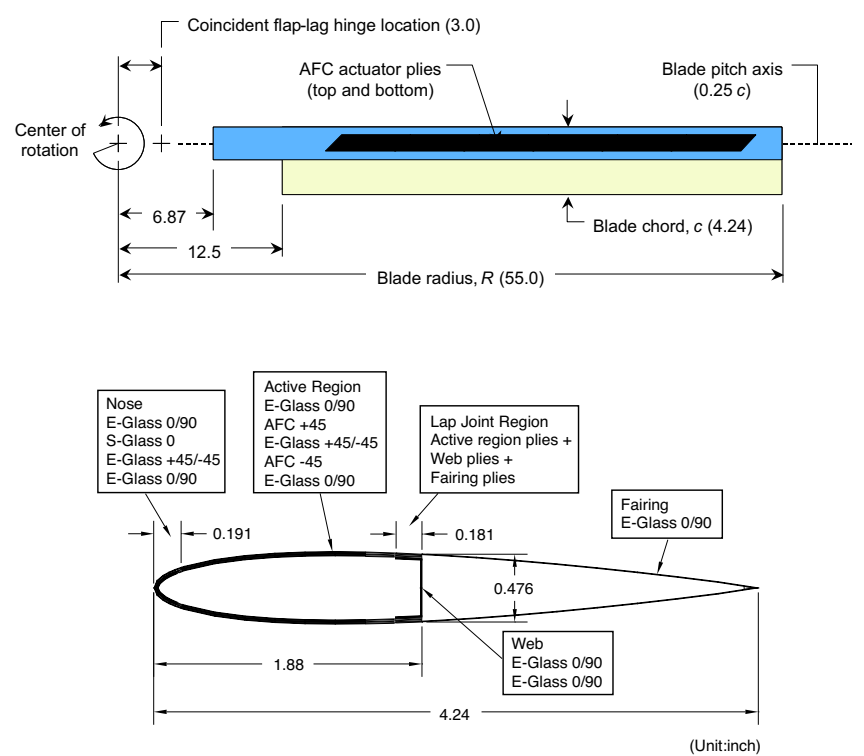

Figure 2: Planform and cross section of the ATR prototype blade (Dimensions are in inches.)

the acceleration potential theory to the rotor aerodynamics problem with a skewed cylindrical wake. More specifically, the induced flow at the rotor disk was expanded in terms of modal functions. As a result, a three-dimensional, unsteady induced-flow aerodynamics model with finite number of states was derived in time domain. This model falls on an intermediate level of wake representation between the simplest momentum and the most complicated free wake methodologies. It does not require a severe computational effort, which is usually the case in those that involve the vortex filament theory. Therefore, this model is applicable to the problems of rotor aeroelastic stability, basic blade-passage vibrations, and higher-harmonic control studies [27].

\section{Aeroelastic System in Forward Flight}

The aeroelastic system of equations which combines the structural and aerodynamic equations obtained in the previous steps is now solved for forward flight condition to provide the information regarding the transient response. Specifically, the present analysis adopts a direct time integration of the blade response due to an integral actuation during flight. This time integration is required since further analytical tasks including system identification, open- and closed-loop simulations will be conducted in time domain. DYMORE, the original passive blade dynamics model, adopts a time-discontinuous integration scheme with energy decaying characteristics in order to avoid high frequency numerical oscillation $[26,30]$. Such an adverse high frequency oscillation usually occurs during a finite element time integration of a complex multi-body dynamic system. Finally, the transfer functions due to 
high voltage actuation input for different forward flight conditions can be calculated by Fourier transform of the time response of the blade or the entire active rotor system.

\section{ATR CHARACTERISTICS}

The basic requirements for the ATR blade comes from an existing passive blade used by NASA Langley. The baseline (passive) system has been well studied and characterized over the years, and is representative of a generic production helicopter [31]. The new ATR blade is designed based on the external dimensions and aerodynamic properties of the existing baseline blade to be tested in heavy gas (R134a) medium. Table 1 summarizes the general dimension and shape characteristics of the ATR blade.

Table 1: Characteristics of the ATR blade

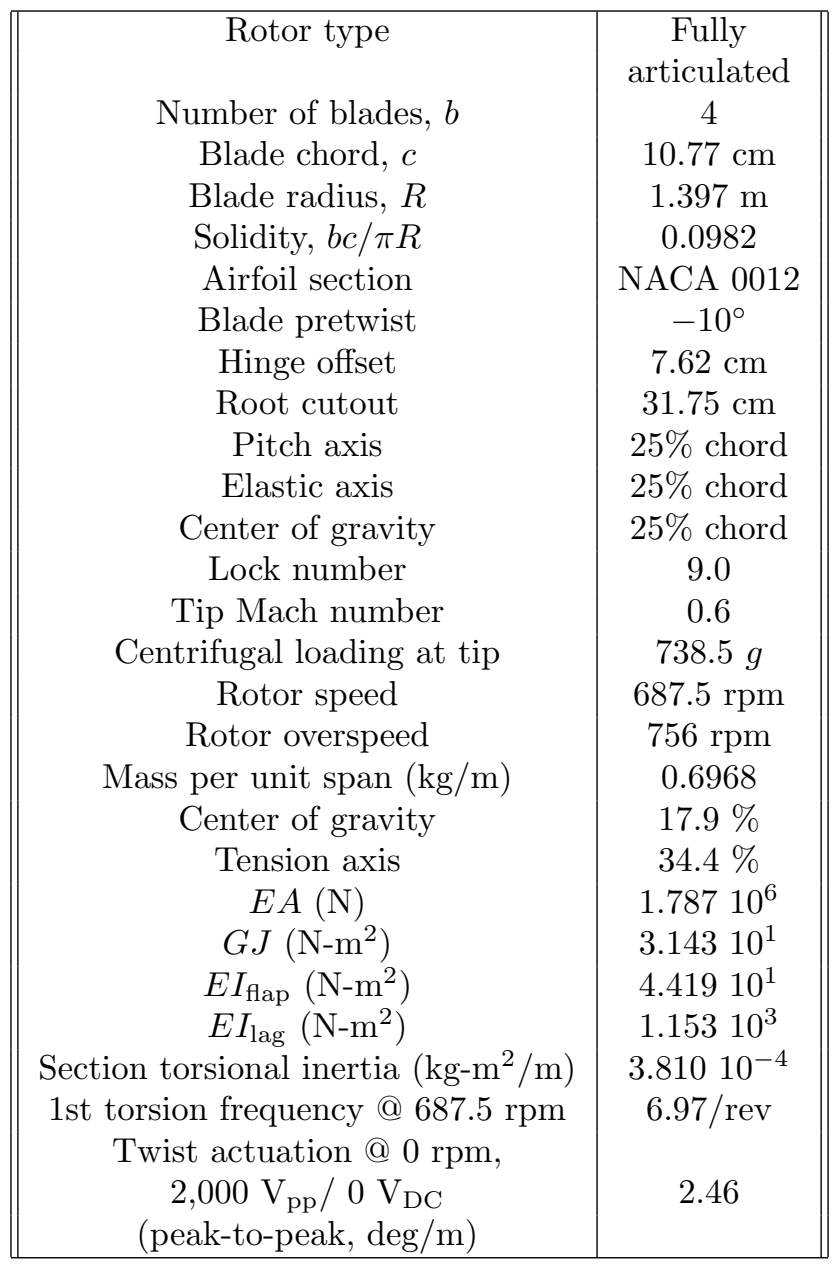

The ATR blade employed a total of 24 AFC packs placed on the front spar only, and distributed in 6 stations along the blade span [21]. Fig. 2 shows basic blade planform and cross section characteristics selected for

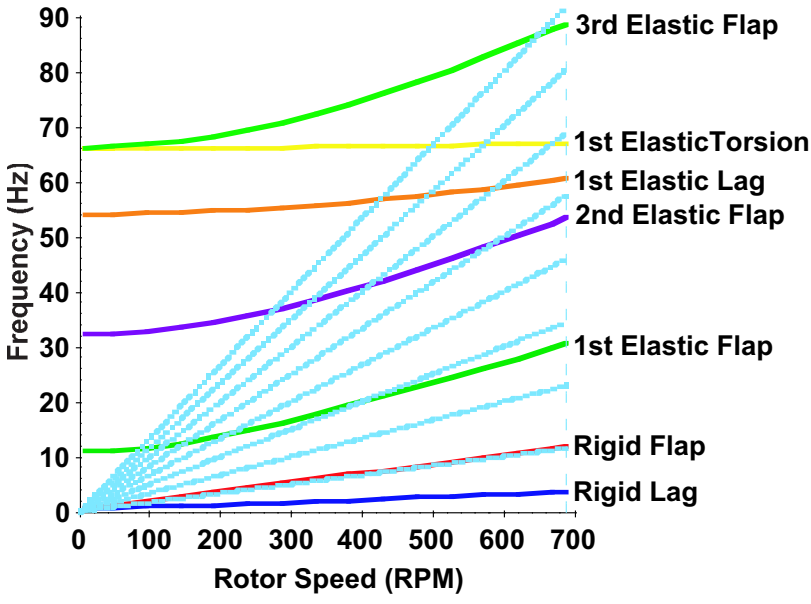

Figure 3: Fan plot of the ATR blade from the proposed analysis

the ATR prototype blade. The material properties of the passive prepregs and the AFC plies used in the blade are summarized in the appendices of Refs. [21] and [24]. The fan plot of the ATR blade is presented in Fig. 3.

\section{OPEN-LOOP FORWARD FLIGHT RESULTS}

The forward flight regime is of great interest for the vibration reduction problem. The blade twist control is suggested to alter the undesirable unsteady aerodynamic environment which develops in that flight regime. In the wind-tunnel test, various flight conditions were selected, and they represented low-speed level flight, high-speed level flight, and descending flight. Once the steady-state equilibrium condition was obtained by adjusting blade pitch control, either sine-dwell or sinesweep high-voltage signal was applied at the embedded actuators. In case of sine-dwell signal, only 3P, 4P, $5 \mathrm{P}$ frequency components were considered since $(N-1$, $N, N+1)$ frequency components are found to influence significantly $N$-bladed rotor system. Two blade control modes were tested: collective twist and an Individual Blade Control (IBC), where all the blades have the same twist actuation variation with azimuth. Experimentally, the collective mode was found to be relatively ineffective in altering fixed-system vibratory loads compared with the IBC mode [19]. The correlations presented here will concentrate on those obtained during the simulated $1 \mathrm{~g}$ level flight conditions while in the baseline (no actuation) and IBC mode of actuation. Also, a sweeping algorithm over control phase angle was considered within the IBC scheme.

Using the proposed forward flight analysis, the open-loop control forward flight test described above is simulated numerically. An input model for a fouractive-bladed fully-articulated rotor system is constructed. Also, a sine-dwell input signal for an IBC 


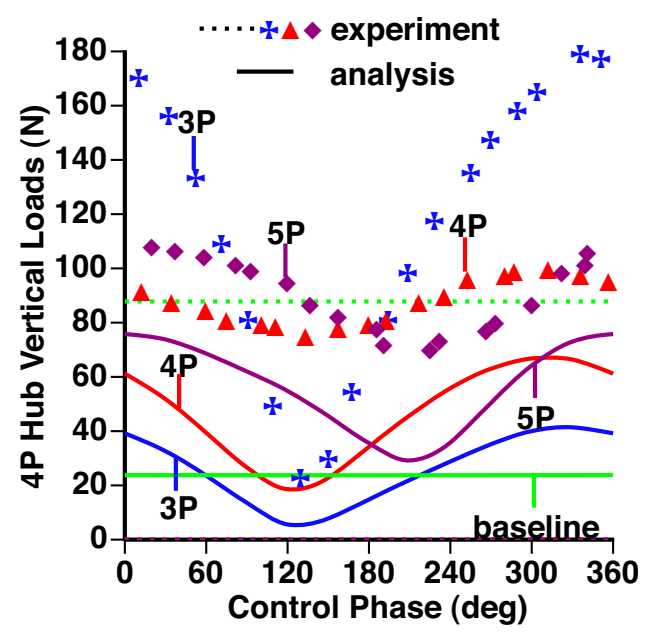

(a) Vertical

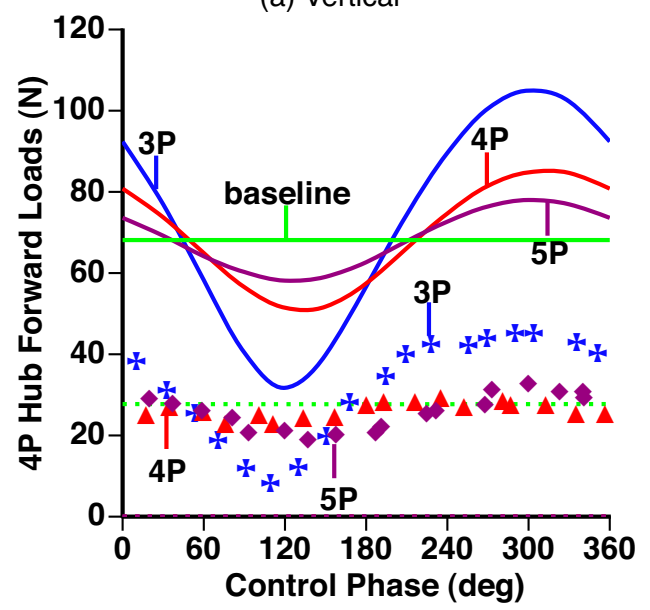

(b) Forward

Figure 4: Variation of $4 \mathrm{P}$ hub shear vibratory loads for $\mu=0.333, \alpha_{S}=-6^{\circ}, C_{T}=0.0066$, and $1,000 \mathrm{~V}$ twist actuation at $3 \mathrm{P}, 4 \mathrm{P}, 5 \mathrm{P}$ with respect to control phase

mode blade actuation is generated with control phase sweeping algorithm. The resulting time domain quantities can be transferred to frequency domain to examine the magnitude of the frequency content of interest, which is $4 \mathrm{P}$ in the four-bladed rotor system. One flight condition is selected among the considered conditions to present the analytical results and its correlation with experiment. The steady-state trim condition is $\mu=0.333, \alpha_{S}=-6^{\circ}, C_{T}=0.0066$.

Fig. 4 shows two components of fixed-system load variation with respect to control phase due to $3 \mathrm{P}, 4 \mathrm{P}$, and 5P IBC mode blade actuation. The load predicted from the analysis shows significant discrepancy in amplitude from the experimental results, although their variation trends in terms of control phase are in good agreement. 3P actuation is most effective in hub shear vibratory load reduction, resulting in $95 \%$ reduction. Such a hub shear vibratory load reduction performance numerically predicted here shows similar trend as it was observed in the experiment. Quantities in the rotatingsystem, for example, flap bending moment and torsional moment are also shown in Figs. 5 and 6. The span location where these quantities are calculated is selected to match those of the strain gauges embedded in the test blade. While the fixed-system quantities were investigated only in $4 \mathrm{P}$ frequency components, those in the rotating-system are extracted and examined in their 3P, $4 \mathrm{P}$, and $5 \mathrm{P}$ frequency components.

Both of fixed- and rotating-system predicted loads exhibit quite a large discrepancy in amplitude from the experimental results. Since the dynamics of the test apparatus used for the wind-tunnel test is not included in the model, this may be responsible for the discrepancies. Upgraded input model for the same ATR system including the pitch link and all the linkage components in the swashplate was attempted for better correlation. However, this increase in model detail has shown little impact on the load prediction.

It should be further noted that the baseline amplitude in all cases are significantly underpredicted by the numerical analysis. Also, the experimental $4 \mathrm{P}$ hub sideward baseline (not shown here) presented unreasonably high magnitude when compared to the other two hub force components. This suggests that further characterization of the whole experimental apparatus is desirable. Once this is done and the information is brought to the model, an improved correlation between them is expected. Meanwhile, the basic active aeroelastic characteristics of the ATR system has been mostly captured by the analysis, and this model is used for further investigations.

\section{SYSTEM IDENTIFICATION RESULTS}

During forward flight, helicopter rotor blade exhibits an aerodynamic environment which varies itself within the rotor revolution. This signifies that the helicopter rotor system during forward flight is basically a linear time-periodic system. Therefore, a methodology considering this periodicity should be used for its characterization. In this paper, a method is adopted which results in multi-component harmonic transfer functions $[28,29]$. The theoretical background of the adopted methodology and its implementation schemes that include additional assumptions imposed on the transfer functions are described in detail in [32].

Sinusoids are used to determine transfer functions, and more specifically, sine-sweep waves (chirp signals) are used to obtain the system response over a specific range of frequencies. Using the sine-sweep input signal, fixed- and rotating-system response of the ATR system are predicted by the proposed analysis. At first, a series 


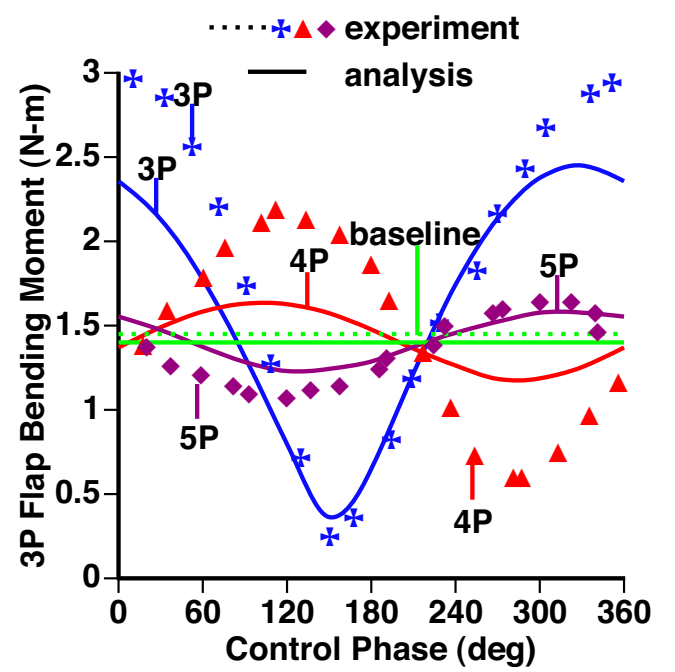

(a) 3P loads

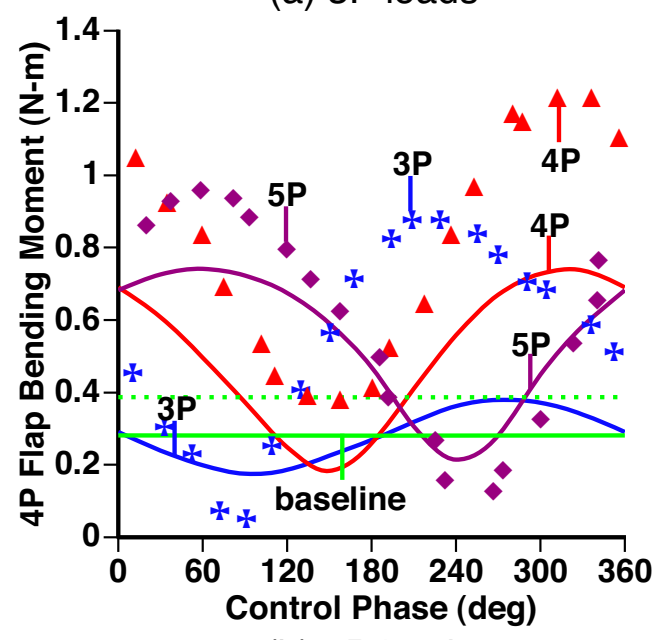

(b) 4P loads

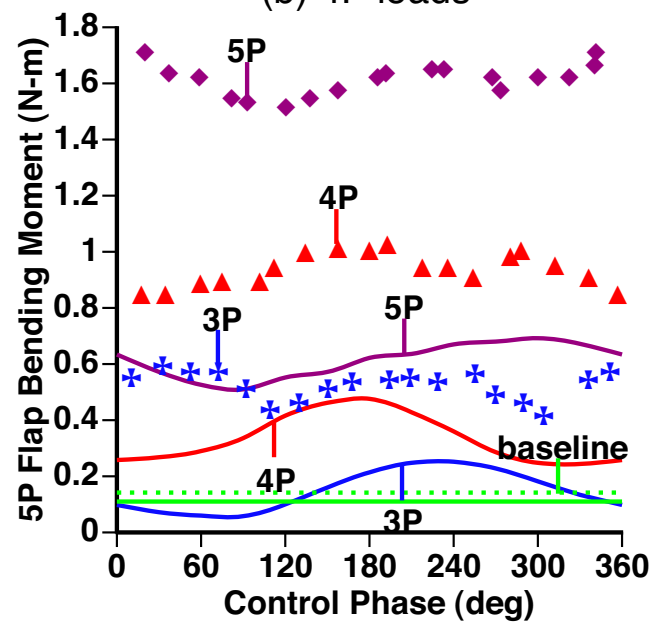

(c) $5 \mathrm{P}$ loads
Figure 5: Variation of flap bending moment at $28.7 \%$ span location for $\mu=0.333, \alpha_{S}=-6^{\circ}, C_{T}=0.0066$, and $1,000 \mathrm{~V}$ twist actuation at $3 \mathrm{P}, 4 \mathrm{P}, 5 \mathrm{P}$ with respect to control phase of collective mode actuation signal is applied, and its response is examined for the system identification. Before applying the system identification algorithm suggested in [32], the amplitude of the baseline loads must be subtracted from those under actuation. This is due to the definition of the transfer matrix which will be used in the future closed-loop controller design, as represented by the following equation.

$$
\mathbf{z}=\mathbf{T u}+\mathbf{z}_{\mathbf{o}}
$$

where $\mathbf{z}$ is a vector of vibration amplitudes, $\mathbf{T}$ is the transfer matrix, $\mathbf{u}$ is the vector of the actuation amplitudes, and $\mathbf{z}_{\mathbf{o}}$ is the vector of the vibration amplitudes with no actuation (baseline).

Five harmonic transfer functions, i.e., $G_{-2}, G_{-1}$, $G_{0}, G_{+1}, G_{+2}$, are obtained, and the higher order ones neglected. However, $G_{0}$ is found to have amplitude which is significantly larger compared with the others. This indicates that the response of the ATR system can be described only by the $G_{0}$ component, behaving like a linear time-invariant (LTI) system. More insight about the blade dynamics can be extracted from a Bode diagram of the $G_{0}$ component for the hub vertical force as shown in Fig. 7. It is recognized that the peaks approximately match the frequencies of rigid and elastic flap bending modes of the blade. (See the fan plot shown in Fig. 3).

Sine-sweep input signals for longitudinal and lateral cyclic mode of blade actuation are also generated. By putting these input signals and executing the same identification process as described before, harmonic transfer functions corresponding to these two modes of actuation are estimated. Again, all the other components except $G_{0}$ resulted in much lower magnitudes. Therefore, the LTI simplification is still valid for these modes of actuation. All the identification results including the collective mode previously obtained may be represented as a transfer matrix relating three components of the hub shear loads versus three modes of blade actuation signal as shown in Fig. 8 .

Consider the case of alleviating only the vertical components of the $4 \mathrm{P}$ hub shear vibratory load. From the analytical results presented in Fig. 4, the baseline amplitude of this vibratory component was predicted to be approximately $23 \mathrm{~N}$. However, from Fig. 8, the amplitudes associated with the hub vertical vibratory load altered by the application of each actuation mode are found to be $45 \mathrm{~N}, 26 \mathrm{~N}$, and $28 \mathrm{~N}$ at $4 \mathrm{P}$ frequency, respectively. Theoretically, it can be concluded that the application of only collective mode of blade actuation is enough for a complete elimination of the $4 \mathrm{P}$ hub vertical vibratory load at this given flight condition. However, experimental results do not support that [19].

This contradiction resulted from the same discrepancy generally found in the load amplitude results pre- 


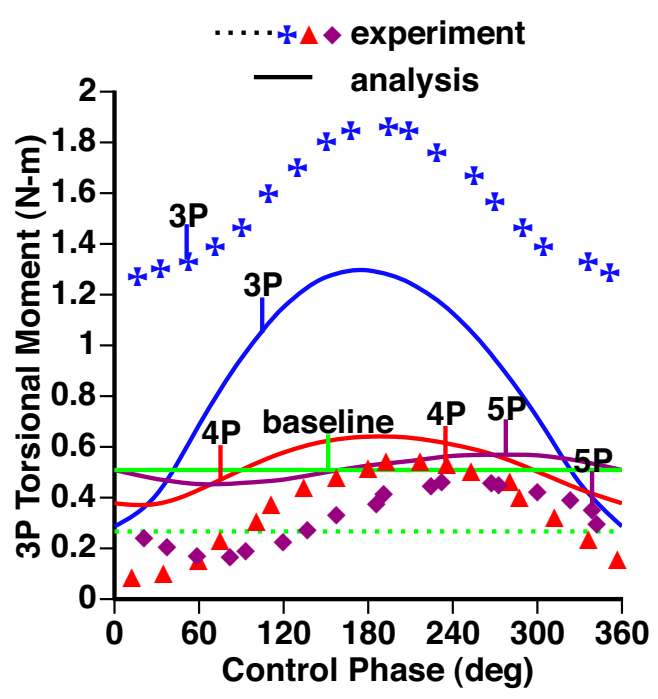

(a) 3P loads

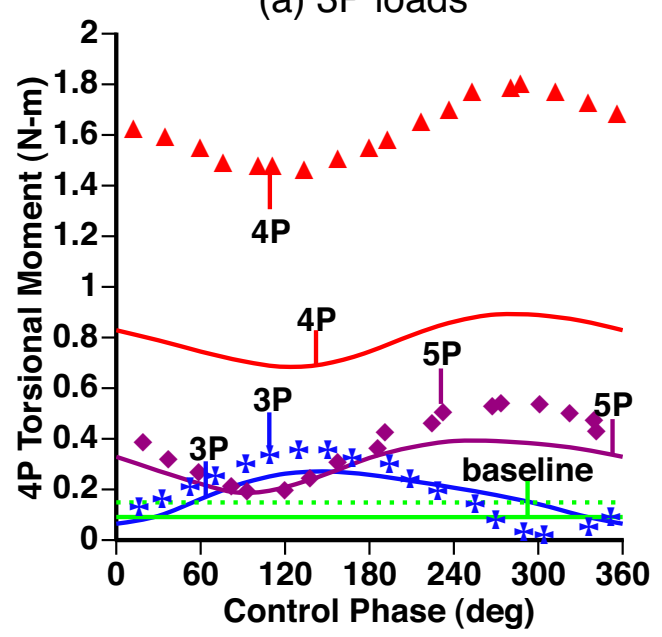

(b) 4P loads

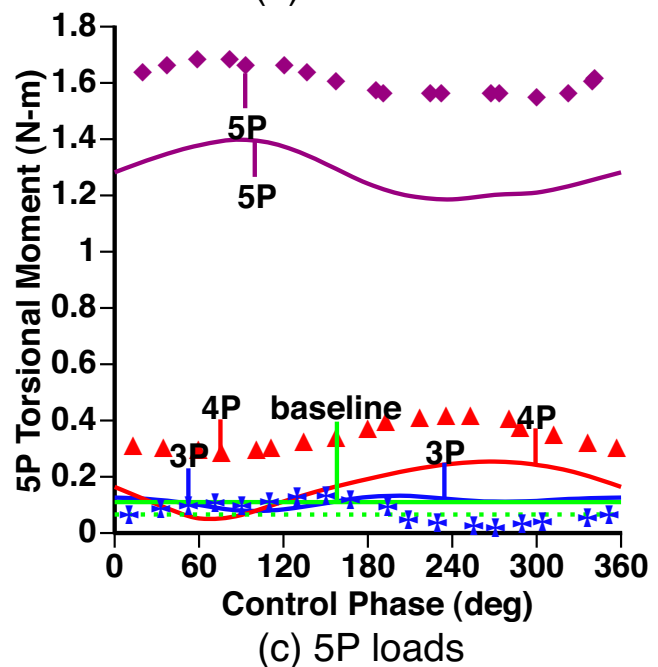

Figure 6: Variation of torsional moment at $33.6 \%$ span location for $\mu=0.333, \alpha_{S}=-6^{\circ}, C_{T}=0.0066$, and $1,000 \mathrm{~V}$ twist actuation at $3 \mathrm{P}, 4 \mathrm{P}, 5 \mathrm{P}$ with respect to control phase
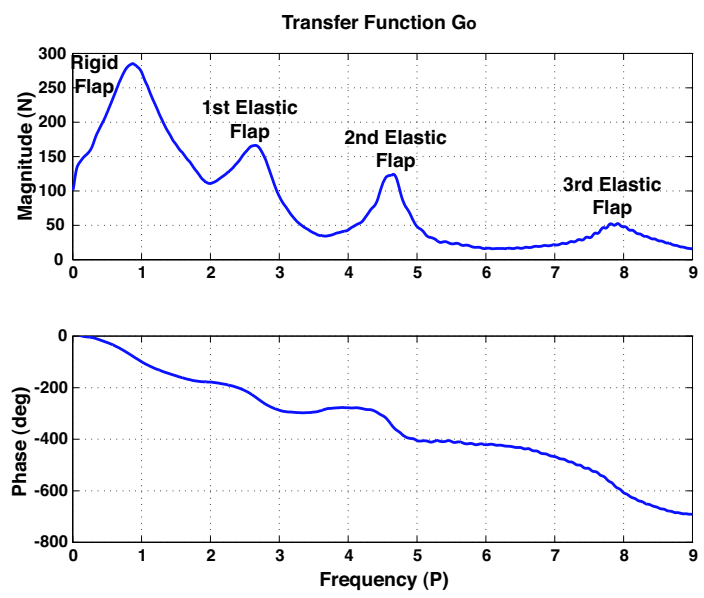

Figure 7: Harmonic transfer function $G_{0}$ of the hub vertical shear loads during the collective mode actuation

dicted by the analysis and observed in the experiment, regarding the baseline loads and those under actuation. Again, for the hub vertical shear vibratory component, the $4 \mathrm{P}$ baseline load was predicted to be $23 \mathrm{~N}$, and the amplitude under collective mode actuation was predicted to be $45 \mathrm{~N}$ at $4 \mathrm{P}$. However, in the experiment, the corresponding quantities for the baseline load was observed to be $90 \mathrm{~N}$ and the amplitude altered by the $4 \mathrm{P}$ IBC-mode actuation to be approximately $20 \mathrm{~N}$ at its maximum (See Fig. 4 (a)). Note that the 4P IBC-mode actuation is exactly the same as the collective mode actuation at $4 \mathrm{P}$.

From the present discussion, few issues are suggested for future study as follows. First, an improvement on the analysis model is recommended regarding its load prediction. Second, regarding the closed-loop control, an appropriate combination of the three actuation modes is recommended. This multi-mode combination becomes equivalent to IBC mode, which was shown to be most effective in the open-loop control test. This multi-mode controller can be configured for suppressing multi-component of hub shear vibratory loads simultaneously.

\section{CONCLUSION}

This paper addresses helicopter vibration reduction using integral blade twist control. As presented here, a numerical aeroelastic framework is proposed for this study. For its implementation, an existing multi-body dynamics code, DYMORE, is modified to account for the distributed anisotropic piezocomposite actuators. The analytical results of open-loop IBC-mode actuation is correlated with the experimental data collected in NASA Langley wind tunnel. While discrepancies are found in the amplitude of the loads under actuation, the 


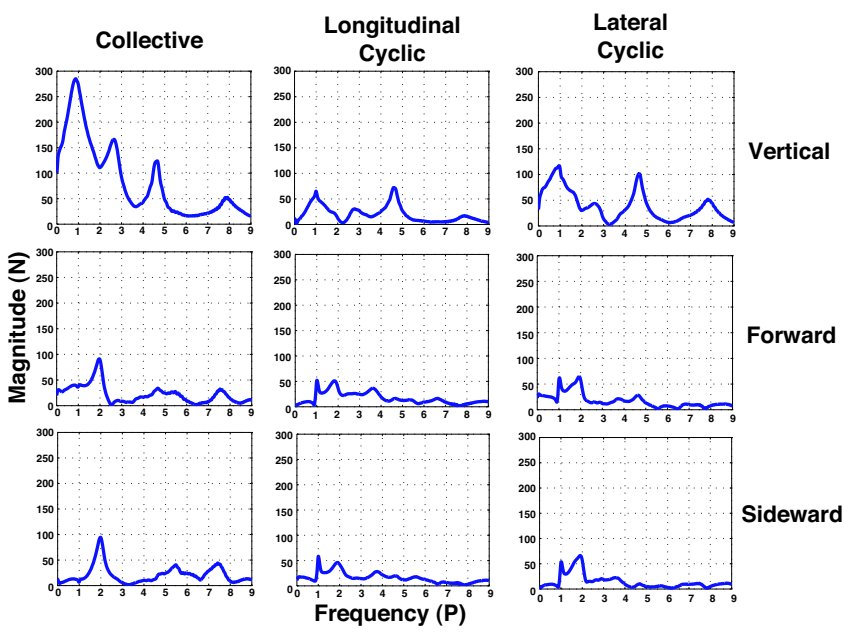

Figure 8: Matrix of $G_{0}$ estimated for three components of $4 \mathrm{P}$ hub shear vibratory loads versus three modes of blade actuation

predicted trend of load variation with respect to its control phase correlates well with the experiments. Using the proposed analysis, system identification on the ATR system is performed. It is found that the linear timeperiodic system can be represented by a linear timeinvariant system under the three modes of blade actuation: collective, longitudinal cyclic, and lateral cyclic. Collective mode of actuation is found to have potential of eliminating $4 \mathrm{P}$ hub vibratory loads completely from the analysis, which contradicts the observation in the experiment. Further studies are required to improve the correlation between the experimental and analytical results. The combination of the three modes of actuation is recommended for future closed-loop control implementations.

\section{ACKNOWLEDGMENTS}

The authors are especially thankful to Mr. Matthew L. Wilbur, Mr. William T. Yeager, Mr. Paul H. Mirick, and Mr. Chester W. Langston (U.S. Army Vehicle Technology Directorate, NASA Langley Research Center) for their support in conducting the forward flight test, to Prof. Olivier A. Bauchau (School of Aerospace Engineering, Georgia Institute of Technology) for providing DYMORE and helping with its modification, and to Prof. Steven R. Hall (Aeronautics and Astronautics, MIT) for his help on system identification. This work was sponsored (at MIT) in part by NASA Langley Research Center under the cooperative agreement \# NCC 1-323.

\section{REFERENCES}

[1] Bielawa, R., Rotary Wing Structural Dynamics and Aeroelasticity, American Institute of Aeronautics and Astronautics, 1992.

[2] Shaw, J., N., Albion, J., Hanker E., and Teal, R. S., "Higher Harmonic Control: Wind Tunnel Demonstration of Fully Effective Vibratory Hub Force Suppression," Journal of the American Helicopter Society, Vol. 31, No. 1, 1989, pp. 14-25.

[3] Ham, N. D., "Helicopter Individual-Blade-Control Research at MIT 1977-1985," Vertica, Vol. 11, No. 1/2, 1987, pp. 109-122.

[4] Molusis, J. A., E., Hammond C., and H., Cline J., "A Unified Approach to the Optimal Design of Adaptive and Gain Scheduled Controllers to Achieve Minimum Helicopter Rotor Vibration," Journal of the American Helicopter Society, Vol. 28, No. 2, 1983, pp. 9-18.

[5] Nguyen, K., Betzina, M., and Kitaplioglu, C., "Full-Scale Demonstration of Higher Harmonic Control for Noise and Vibration Reduction on the XV-15 Rotor," In Proceedings of the American Helicopter Society 56th Annual Forum, Virginia Beach, Virginia, May 2-4 2000.

[6] Wood, E. R., Powers, R. W., Cline, J. H., and Hammond, C. E., "On Developing and Flight Testing a Higher Harmonic Control System," Journal of the American Helicopter Society, Vol. 30, No. 1, 1985, pp. 3-20.

[7] Loewy, R. G., "Recent Developments in Smart Structures with Aeronautical Applications," In Proceedings of the 37th Israel Annual Conference on Aerospace Sciences, February 26-27 1997.

[8] Friedmann, P. P., "The Promise of Adaptive Materials for Alleviating Aeroelastic Problems and Some Concerns," In Proceedings of Innovation in Rotorcraft Technology, London, United Kingdom, June 24-25 1997, Royal Aeronautical Society, pp. 10.1-10.16.

[9] Chopra, I., "Status of Application of Smart Structures Technology to Rotorcraft Systems," Journal of the American Helicopter Society, Vol. 45, No. 4, 2000, pp. 228-252.

[10] Giurgiutiu, V., "Recent Advances in SmartMaterial Rotor Control Actuation," In Proceedings of the AIAA/ASME/ASCE/AHS/ASC 41st Structures, Structural Dynamics and Materials Conference- Adaptive Structures Forum, Atlanta, Georgia, April 3-6 2000, AIAA Paper No. 20001709. 
[11] Barrett, R., "Intelligent Rotor Blade Structures Development Using Directionally Attached Piezoelectric Crystals," M.S. thesis, University of Maryland, College Park, Maryland, 1990.

[12] Chen, P. C. and Chopra, I., "Hover Testing of Smart Rotor with Induced-Strain Actuation of Blade Twist," AIAA Journal, Vol. 35, No. 1, 1997, pp. 6-16.

[13] Rodgers, J. P. and Hagood, N. W., "Development of an Integral Twist-Actuated Rotor Blade for Individual Blade Control," AMSL \# 98-6, Massachusetts Institute of Technology, October 1998.

[14] Cesnik, C. E. S., Shin, S.-J., Wilkie, W. K., Wilbur, M. L., and Mirick, P. H., "Modeling, Design, and Testing of the NASA/ARMY/MIT Active Twist Rotor Prototype Blade," In Proceedings of the American Helicopter Society 55th Annual Forum, Montreal, Canada, May 25-27 1999.

[15] Derham, R. C. and Hagood, N. W., "Rotor Design Using Smart Materials to Actively Twist Blades," In Proceedings of the American Helicopter Society 52nd Annual Forum, Washington, DC, June 4-6 1996.

[16] Wilbur, M. L., Yeager, Jr. W. T., Wilkie, W. K., Cesnik, C. E. S., and Shin, S.-J., "Hover Testing of the NASA/ARMY/MIT Active Twist Rotor Prototype Blade," In Proceedings of the American Helicopter Society 56th Annual Forum, Virginia Beach, Virginia, May 2-4 2000.

[17] duPlessis, A. J. and Hagood, N. W., "Modeling and Experimental Testing of Twist Actuated Single Cell Composite Beams for Helicopter Blade Control," AMSL \# 96-1, Massachusetts Institute of Technology, February 1996.

[18] Derham, R. C., Matthew, B., and Weems, D. B., "An Introduction to the Aeromechanical Design Space of "Smart" Rotors," In Proceedings of the American Helicopter Society Northeast Region National Specialists' Meeting - Improving Rotorcraft Acceptance through Active Controls Technlogy, Bridgeport, Connecticut, October 4-5 2000.

[19] Wilbur, M. L., Mirick, P. H., Yeager, Jr. W. T., Langston, C. W., Cesnik, C. E. S., and Shin, S.J., "Vibratory Loads Reduction Testing of the NASA/ARMY/MIT Active Twist Rotor," In Proceedings of the American Helicopter Society 57th Annual Forum, Washington, DC, May 9-11 2001.

[20] Cesnik, C. E. S. and Shin, S.-J., "On the Modeling of Integrally Actuated Helicopter Blades," International Journal of Solids and Structures, Vol. 38, No. 10-13, 2001, pp. 1765-1789.
[21] Shin, S.-J. and Cesnik, C. E. S., "Design, Manufacturing and Testing of an Active Twist Rotor," AMSL \# 99-3, Massachusetts Institute of Technology, June 1999.

[22] Cesnik, C. E. S., Shin, S.-J., and Wilbur, M. L., "Dynamic Response of Active Twist Rotor Blades," Smart Materials and Structures-Special Issue on Rotorcraft Applications, Vol. 10, 2001, pp. $62-76$.

[23] Shin, S.-J. and Cesnik, C. E. S., "Forward Flight Response of the Active Twist Rotor for Helicopter Vibration Reduction," In Proceedings of the 42nd AIAA Structures, Structural Dynamics, and Materials Conference, Seattle, Washington, April 16-19 2001, AIAA Paper 2001-1357.

[24] Shin, S.-J. and Cesnik, C. E. S., "Integral Twist Actuation of Helicopter Rotor Blades for Vibration Reduction," AMSL \# 01-07, Massachusetts Institute of Technology, August 2001.

[25] Cesnik, C. E. S. and Ortega-Morales, M., "Active Composite Beam Cross-Sectional Modeling - Stiffness and Active Force Constants," In Proceedings of the 40th AIAA Structures, Structural Dynamics, and Materials Conference, St. Louis, Missouri, April 12-15 1999, AIAA Paper No. 99-1548.

[26] Bauchau, O. A., "Computational Schemes for Flexible, Nonlinear Multi-Body Systems," Multibody System Dynamics, Vol. 2, 1998, pp. 169-225.

[27] Peters, D. A. and He, C. J., "Finite State Induced Flow Models Part II: Three-Dimensional Rotor Disk," Journal of Aircraft, Vol. 32, No. 2, 1995, pp. 323-333.

[28] Wereley, N. M. and Hall, S. R., "Linear Time Periodic Systems: Transfer Functions, Poles, Transmission Zeros and Directional Properies," In Proceedings of the 1991 American Control Conference, Boston, Massachusetts, June 26-28 1991.

[29] Nitzsche, F., "Laplace-Domain Approximation to the Transfer Functions of a Rotor Blade in Forward Flight," The Aeronautical Journal, Vol. 105, No. 1077, 2001, pp. 233-240.

[30] Theron, N. J., Multi-Body Dynamic Analysis of Helicopter Rotors, $\mathrm{PhD}$ dissertation, Rensselaer Polytechnic Institute, 1994.

[31] Wilkie, W. K., Wilbur, M. L., Mirick, P. H., Cesnik, C. E. S., and Shin, S.-J., "Aeroelastic Analysis of the NASA/ARMY/MIT Active Twist Rotor," In Proceedings of the American Helicopter Society 55th Annual Forum, Montreal, Canada, May 25271999. 
[32] Siddiqi, A. and Hall, S. R., "Identification of the Harmonic Transfer Functions of a Helicopter Rotor," AMSL \# 01-01, Massachusetts Institute of Technology, March 2001. 